\title{
$\alpha$-Linolenic acid, linoleic acid and heart failure in women
}

\author{
Emily B. Levitan ${ }^{1 *}$, Alicja Wolk², Niclas Håkansson² and Murray A. Mittleman ${ }^{3,4}$ \\ ${ }^{1}$ Department of Epidemiology, School of Public Health, University of Alabama at Birmingham, RPHB 230K, $15303 \mathrm{rd}$ \\ Avenue S, Birmingham, AL 35294-0022, USA \\ ${ }^{2}$ Division of Nutritional Epidemiology, Institute of Environmental Medicine, Karolinska Institute, Stockholm, Sweden \\ ${ }^{3}$ Cardiovascular Epidemiology Research Unit, Harvard Medical School, Beth Israel Deaconess Medical Center, \\ Boston, MA, USA \\ ${ }^{4}$ Department of Epidemiology, Harvard School of Public Health, Boston, MA, USA
}

(Submitted 6 June 2011 - Final revision received 7 November 2011 - Accepted 8 November 2011 - First published online 15 December 2011)

\section{Abstract}

$\alpha$-Linolenic acid (18:3n-3) intake and linoleic acid (18:2n-6) intake have been associated with lower rates of CHD, though results have not been consistent. The relationship of these fatty acids with incident heart failure (HF) is not well established. We examined the hypothesis that women with higher intakes of $18: 3 n-3$ and $18: 2 n-6$ would have lower rates of HF hospitalisation and mortality. We measured 18:3n-3 and 18:2n-6 intake in 36234 Swedish Mammography Cohort participants aged 48-83 years using FFQ and followed participants through Swedish inpatient and cause-of-death registers from 1 January 1998 until 31 December 2006. Cox models were used to calculate incidence rate ratios (RR) and 95\% CI. Because of multicollinearity, 18:3n-3 and 18:2n-6 were examined separately. Over 9 years, 596 women were hospitalised and fifty-five died due to HF. In models accounting for age and other covariates, the RR for HF comparing the top quintile of $18: 3 n-3$ (median $1.50 \mathrm{~g} / \mathrm{d}$ ) with the bottom quintile (median $0.88 \mathrm{~g} / \mathrm{d}$ ) was $0.91\left(95 \% \mathrm{CI} 0 \cdot 71,1 \cdot 17, P_{\text {trend }}=0 \cdot 41\right)$. The RR comparing the top quintile of $18: 2 n-6$ (median $7 \cdot 8 \mathrm{~g} / \mathrm{d}$ ) with the bottom quintile (median $4.6 \mathrm{~g} / \mathrm{d}$ ) was $1 \cdot 14\left(95 \% \mathrm{CI} 0 \cdot 88,1 \cdot 46, P_{\text {trend }}=0 \cdot 36\right)$. We did not find evidence for the interaction of $18: 3 n-3$ and $18: 2 n-6$ with each other or with long-chain $n-3$ fatty acids. In conclusion, these data do not support our hypothesis that $18: 3 n-3$ and $18: 2 n-6$ are associated with HF. However, these results may not be generalisable to populations with higher intakes of $18: 3 n-3$.

Key words: Heart failure: $\boldsymbol{\alpha}$-Linolenic acid: Linoleic acid

Heart failure (HF) is an end-stage CVD with a lifetime risk of approximately $20 \%{ }^{(1)}$. Although treatment for $\mathrm{HF}$ has improved, death rates are still high; mortality is more than $20 \%$ within 1 year of diagnosis ${ }^{(2)}$. In order to reduce the public health impact of $\mathrm{HF}$, prevention strategies are needed $^{(3)}$. One non-pharmacological target for intervention is diet. However, the relationship of diet with the development of $\mathrm{HF}$ is largely unknown, and existing dietary strategies to prevent or ameliorate HF risk factors such as hypertension and diabetes are underutilised ${ }^{(3)}$.

Supplementation with the long-chain $n$-3 PUFA EPA and DHA, found primarily in fish, may reduce mortality in patients with myocardial infarction (MI) and $\mathrm{HF}^{(4,5)}$, and dietary intake is associated with lower rates of CVD including sudden death ${ }^{(6)}, \mathrm{CHD}^{(7)}$ and $\mathrm{HF}^{(8-11)}$. The plant-derived $n-3$ fatty acid $\alpha$-linolenic acid $(18: 3 n-3)$ is more abundant in the food supply than long-chain $n$ - 3 fatty acids, and $18: 3 n-3$ can be metabolised into the long-chain $n-3$ fatty acids, although at a low rate ${ }^{(12)}$. This rate is even lower in people with a substantial dietary intake of long-chain $n$-3 fatty acids ${ }^{(12)}$. A higher intake of $18: 3 n-3$ has been associated with a lower rate of CHD in some populations ${ }^{(13-15)}$, but a recent study did not find an association with $\mathrm{HF}^{(16)}$. Overall, supplementation with neither $18: 3 n-3$ nor long-chain $n-3$ fatty acids significantly reduced major cardiovascular events in a recent trial in people with a history of $\mathrm{MI}^{(17)}$. However, among the women in the trial, those who received 18:3n-3 had a $27 \%$ lower rate of major cardiovascular events, which approached statistical significance $(P=0 \cdot 07)^{(17)}$.

The most prevalent PUFA in the food supply is $n-6$ linoleic acid $(18: 2 n-6)^{(18)}$. 18:2n-6 competes with $18: 3 n-3$ for elongation enzymes, and the intake of one fatty acid may modify the effect of the other ${ }^{(12)}$. Because $18: 2 n-6$ is a metabolic precursor to inflammatory eicosanoids, there has been concern that too much $18: 2 n-6$ or an imbalance in the ratio of $n-6: n-3$ fatty acids may increase the risk of $\mathrm{CVD}^{(19)}$. However, in studies of human subjects, higher $18: 2 n-6$ was not associated with an increase in inflammation ${ }^{(20)}$. Substituting

Abbreviations: HF, heart failure; MI, myocardial infarction; RR, rate ratio.

*Corresponding author: E. B. Levitan, fax +1 205934 8665, email elevitan@uab.edu 
18:2n-6 for carbohydrate decreases LDL-cholesterol and increases HDL-cholesterol, which is expected to result in lower cardiovascular risk ${ }^{(21)}$. In addition, 18:2n-6 consumption has been inversely associated with the rate of CHD in some studies ${ }^{(14,20,22)}$, though many studies have found no significant association $^{(19,20)}$.

We hypothesised that a higher intake of both $18: 3 n-3$ and $18: 2 n-6$ would reduce the risk of HF. We examined the associations of $18: 3 n-3$ and $18: 2 n-6$ with HF hospitalisation and mortality in a population of middle-aged and older women. Because some studies have suggested that the health effects of 18:3n-3 may depend on the intake of long-chain $n-3$ fatty acids and $18: 2 n-6^{(12,14)}$, we examined whether the associations varied by the intake of other PUFA.

\section{Methods \\ Participants}

The present study included participants in the Swedish Mammography Study. The recruitment process, characteristics of the cohort and study methods have previously been described in detail ${ }^{(23)}$. Women born between 1914 and 1948 and living in Västmanland and Uppsala counties in central Sweden received a questionnaire between 1 March 1987 and 14 December 1990. Of the 90303 women identified in the population register, $66651(74 \%)$ returned a completed questionnaire. In September 1997, a second questionnaire was sent to 56030 participants who were still alive and residing in the study area; 39227 (70\%) returned a questionnaire. Because information on cardiovascular risk factors such as cigarette smoking was collected on the second questionnaire, only women who completed the 1997 questionnaire were included in the present study. The present study is based on information from the 1997 questionnaire.

Participants who did not provide or provided incorrect national identification numbers, who reported implausible energy intakes ( $>3$ standard deviations from the natural logarithm-transformed mean), who had a previous diagnosis of cancer (other than non-melanoma skin cancer) or HF were excluded ( $n$ 1126). Because patients with diabetes or MI are often counselled to alter their diets and diabetes and MI are risk factors for $\mathrm{HF}$, only women with no baseline history of $\mathrm{MI}$ or diabetes were included ( $n$ 36234). History of HF and MI was determined through record linkage to the Swedish inpatient register, and diabetes was determined using self-report and record linkage. The study was conducted according to the guidelines laid down in the Declaration of Helsinki and all procedures involving human subjects/patients were approved by the Regional Ethical Review Board at Karolinska Institute, Stockholm, Sweden. Completion and return of the selfadministered questionnaire was assumed to imply consent.

\section{Diet assessment}

Self-administered food-frequency items on the questionnaires asked participants to report usual frequency of consumption of ninety-six items over the previous year. For foods and beverages such as milk, coffee, cheese and bread that are commonly eaten in Sweden, participants reported their consumption in servings per $\mathrm{d}$ or per week. For other foods and beverages, there were eight predefined responses ranging from never to $\geq 3$ times/d. For each food and beverage, total consumption was calculated by multiplying the frequency of consumption by age-specific portion sizes which were determined using weighed dietary records. Nutrient values were calculated by multiplying the food or beverage intake by the nutrient composition obtained from the Swedish National Food Administration ${ }^{(24)}$ and summing over foods and beverages. Nutrient intakes were adjusted for energy using the residual method ${ }^{(25)}$. Among 239 women included in a study of the questionnaire performance, correlations between FFQ and adipose tissue biopsies were 0.34 for $18: 3 n-3$ and 0.36 for 18:2n-6 (A Wolk, unpublished results).

\section{Heart failure follow-up}

Participants were followed from 1 January 1998 until 31 December 2006 through record linkage to the Swedish inpatient and cause-of-death registers. The inpatient register captures more than $99 \%$ of inpatient care in Sweden. HF events were defined as hospitalisations for or deaths from HF identified by codes 428 (International Classification of Disease-9), I50 or I11.0 (International Classification of Disease-10) listed as the primary diagnosis. In a previous study, $95 \%$ of people with these codes as the primary diagnosis had confirmed $\mathrm{HF}$ on medical record review using the European Society of Cardiology criteria ${ }^{(26)}$. We included the first $\mathrm{HF}$ event recorded in the registers for each individual.

\section{Statistical analysis}

Because some participants were missing data on weight or height to calculate BMI (1.7\%) and physical activity (22.4\%), we used Markov chain Monte Carlo multiple imputation to simulate five complete datasets. Statistical analyses were performed in each of the datasets separately, and the results were then averaged and the $\mathrm{CI}$ and $P$ values calculated accounting for uncertainty in the imputed estimates ${ }^{(27)}$.

We computed means and percentages of demographic, behavioural and health covariates by quintiles of intake of $18: 3 n-3$ and $18: 2 n-6$. To estimate the incidence rate ratios (RR) associated with $18: 3 n-3$ and $18: 2 n-6$, we used Cox proportional hazards models that accounted for age by allowing the baseline hazard to vary ${ }^{(28)}$. We adjusted for BMI (linear), physical activity (linear), energy intake (linear), alcohol consumption (linear), fibre consumption (linear), Na consumption (linear), education (less than high school, high school or university), family history of myocardial infarction at $<60$ years (yes or no), cigarette smoking (current, past or never), living alone (yes or no), postmenopausal hormone use (yes or no), self-reported history of hypertension (yes or no) and self-reported history of high cholesterol (yes or no). Nutrient replacement models that additionally adjusted for all but one of the macronutrients demonstrated multicollinearity (highest condition index $=378$ ), suggesting that results of the models 
could be severely biased. We tested for linear trend by entering the median $18: 3 n-3$ or $18: 2 n-6$ in each quintile as a continuous variable. Assuming a HF rate of two cases per 1000 person-years based on preliminary data and setting the significance level to 0.05 , we estimated that there would be at least $80 \%$ power to detect a RR of 0.72 or lower and 1.47 or higher comparing top with bottom quintiles using the Schoenfeld \& Richter approach ${ }^{(29)}$.

We examined the associations with $18: 3 n-3$ and $18: 2 n-6$ modelled as continuous exposures, expressed as percentage of total fat. We explored the effect of measurement error in $18: 3 n-3$ and $18: 2 n-6$ using the regression calibration approach $^{(25)}$ and additional data from the 239 women with fat biopsies. We examined whether the association between $18: 3 n-3$ and the incidence of HF hospitalisation or mortality varied by long-chain $n$ - 3 intake above or below the median $(0 \cdot 30 \mathrm{~g} / \mathrm{d})$ and by $18: 2 n-6$ above or below the median $(5.9 \mathrm{~g} / \mathrm{d})$. We tested for interaction by including the product of the median in each quintile for $18: 3 n-3$ and an indicator for being above the median intake of long-chain $n-3$ or $18: 2 n-6$ in the models. Similarly, we examined whether the relationship between 18:2n-6 intake and the incidence of HF hospitalisation or mortality varied by long-chain $n-3$ intake and 18:3n-3 intake above or below the median. We examined the relationship between the major food sources of variability in $18: 3 n-3$ and $18: 2 n-6$ intake and the incidence of HF hospitalisation or mortality. Because symptoms of HF occurring before hospitalisation or death may influence dietary behaviour, we performed a sensitivity analysis excluding cases occurring during the first 2 years of follow-up. We tested for violations of the proportional hazards assumption by entering the product of $18: 3 n-3$ or $18: 2 n-6$ and the natural logarithm of time in the model. The proportional hazards assumption did not appear to be violated.

Statistical analyses were performed using SAS version 9.1. A two-sided $P$ value $<0.05$ was considered statistically significant.

\section{Results}

Over 9 years of follow-up, 651 of the 36234 women were hospitalised for HF ( $n$ 596) or died of HF ( $n$ 55). Intake of $18: 3 n-3$ and $18: 2 n-6$ was highly correlated $(r 0 \cdot 79)$. On average, $2 \%$ of fat consumed was $18: 3 n-3$ and $10 \%$ was $18: 2 n-6$. Compared with women in the lowest quintile of $18: 3 n-3$ intake, women in the highest quintile were more likely to be current smokers (Table 1). On average, they consumed more fibre, $\mathrm{Na}$, saturated fat and long-chain $n$-3 fatty acids, and less alcohol, protein and carbohydrate. Foods that contributed to the variability in $18: 3 n-3$ intake included soya products, mayonnaise and salad dressing; however, the absolute intake of these foods was low. Compared with women in the lowest quintile of $18: 2 n-6$ intake, women in the highest quintile were on average younger, more likely to be current

Table 1. Characteristics of 36234 women aged $48-83$ years by $\alpha$-linolenic acid consumption

(Mean values and standard deviations; percentages)

\begin{tabular}{|c|c|c|c|c|c|c|c|c|c|c|}
\hline & \multicolumn{2}{|c|}{ Quintile 1} & \multicolumn{2}{|c|}{ Quintile 2} & \multicolumn{2}{|c|}{ Quintile 3} & \multicolumn{2}{|c|}{ Quintile 4} & \multicolumn{2}{|c|}{ Quintile 5} \\
\hline & Mean & SD & Mean & SD & Mean & SD & Mean & SD & Mean & $\mathrm{SD}$ \\
\hline Age (years) & $62 \cdot 5$ & $9 \cdot 4$ & $61 \cdot 7$ & $9 \cdot 1$ & 61.4 & $9 \cdot 0$ & 61.4 & $9 \cdot 1$ & $61 \cdot 1$ & $9 \cdot 2$ \\
\hline BMI $\left(\mathrm{kg} / \mathrm{m}^{2}\right)$ & $25 \cdot 0$ & 3.9 & $25 \cdot 1$ & $3 \cdot 8$ & $25 \cdot 0$ & 3.9 & $25 \cdot 0$ & 3.9 & $24 \cdot 8$ & $4 \cdot 0$ \\
\hline Physical activity (metabolic equivalent $\mathrm{h} / \mathrm{d}$ ) & $42 \cdot 3$ & 4.9 & $42 \cdot 6$ & $4 \cdot 7$ & $42 \cdot 4$ & $4 \cdot 7$ & $42 \cdot 5$ & $4 \cdot 7$ & $42 \cdot 4$ & $4 \cdot 8$ \\
\hline \multicolumn{11}{|l|}{ Cigarette smoking (\%) } \\
\hline Current & \multicolumn{2}{|c|}{$20 \cdot 7$} & \multicolumn{2}{|c|}{$21 \cdot 1$} & \multicolumn{2}{|c|}{$21 \cdot 8$} & \multicolumn{2}{|c|}{$23 \cdot 3$} & \multicolumn{2}{|c|}{$27 \cdot 2$} \\
\hline Past & \multicolumn{2}{|c|}{$22 \cdot 8$} & \multicolumn{2}{|c|}{$22 \cdot 4$} & \multicolumn{2}{|c|}{$23 \cdot 2$} & \multicolumn{2}{|c|}{21.9} & \multicolumn{2}{|c|}{$22 \cdot 5$} \\
\hline Never & \multicolumn{2}{|c|}{$56 \cdot 5$} & \multicolumn{2}{|c|}{$56 \cdot 5$} & \multicolumn{2}{|c|}{$55 \cdot 0$} & \multicolumn{2}{|c|}{$54 \cdot 8$} & \multicolumn{2}{|c|}{$50 \cdot 3$} \\
\hline \multicolumn{11}{|l|}{ Education (\%) } \\
\hline Less than high school & \multicolumn{2}{|c|}{$72 \cdot 8$} & \multicolumn{2}{|c|}{$75 \cdot 1$} & \multicolumn{2}{|c|}{$75 \cdot 2$} & \multicolumn{2}{|c|}{$74 \cdot 0$} & \multicolumn{2}{|c|}{$71 \cdot 3$} \\
\hline High school & \multicolumn{2}{|c|}{$8 \cdot 1$} & & & & & & & & \\
\hline University & & & & & & & & & & \\
\hline Living alone (\%) & & & & & & & & & & \\
\hline History of hypertension (\%) & & & & & & & & & & \\
\hline History of high cholesterol (\%) & & & & & & & & & & \\
\hline Postmenopausal hormone therapy (\%) & & & & & & & & & & \\
\hline Family history of myocardial infarction (\%) & & & & & & & & & & \\
\hline Energy intake (kJ/d) & 7326 & 2318 & 7230 & 2134 & 7226 & 2109 & 7272 & 2100 & 7326 & 2305 \\
\hline Alcohol (g/d) & $4 \cdot 4$ & 6.5 & $4 \cdot 1$ & 4.9 & $4 \cdot 1$ & 4.9 & $4 \cdot 2$ & $4 \cdot 8$ & $4 \cdot 1$ & $4 \cdot 8$ \\
\hline Fibre (g/d) & $21 \cdot 1$ & $5 \cdot 8$ & 21.9 & $5 \cdot 3$ & $22 \cdot 1$ & $5 \cdot 2$ & $22 \cdot 2$ & $5 \cdot 2$ & 22.9 & $5 \cdot 8$ \\
\hline $\mathrm{Na}(\mathrm{g} / \mathrm{d})$ & 2385 & 387 & 2499 & 350 & 2547 & 360 & 2574 & 364 & 2618 & 441 \\
\hline Protein (g/d) & $72 \cdot 8$ & $14 \cdot 0$ & 71.5 & $11 \cdot 0$ & $70 \cdot 7$ & $10 \cdot 4$ & $69 \cdot 7$ & $10 \cdot 0$ & $67 \cdot 6$ & $10 \cdot 6$ \\
\hline Carbohydrate $(\mathrm{g} / \mathrm{d})$ & $220 \cdot 8$ & $30 \cdot 0$ & 215 & 25 & 211 & 24 & 207 & 23 & 200 & 24 \\
\hline Saturated fat $(\mathrm{g} / \mathrm{d})$ & $26 \cdot 1$ & $7 \cdot 0$ & $26 \cdot 7$ & $6 \cdot 1$ & $27 \cdot 3$ & 5.9 & $27 \cdot 9$ & 5.9 & $28 \cdot 7$ & $6 \cdot 5$ \\
\hline Linoleic acid (g/d) & $4 \cdot 7$ & 0.7 & 5.5 & 0.7 & $6 \cdot 0$ & 0.8 & $6 \cdot 5$ & 0.9 & 7.9 & $2 \cdot 1$ \\
\hline$\alpha$-Linolenic acid (g/d) & 0.86 & 0.09 & 1.03 & 0.04 & $1 \cdot 15$ & 0.03 & $1 \cdot 28$ & 0.04 & 1.56 & 0.22 \\
\hline Long-chain n-3 PUFA (g/d) & $0 \cdot 30$ & 0.20 & 0.33 & 0.21 & 0.36 & 0.25 & 0.36 & 0.26 & 0.37 & 0.31 \\
\hline Soya products (servings/week) & $0 \cdot 1$ & 0.2 & 0.2 & 0.3 & 0.2 & 0.4 & 0.3 & 0.5 & 0.6 & 1.7 \\
\hline Nuts (servings/week) & 0.3 & 0.6 & 0.3 & 0.7 & 0.3 & 0.7 & 0.4 & 0.7 & 0.4 & $1 \cdot 1$ \\
\hline Mayonnaise (servings/week) & 0.3 & 0.4 & 0.3 & 0.4 & 0.4 & 0.5 & 0.5 & 0.6 & 0.7 & 1.65 \\
\hline Salad dressing (servings/week) & 0.5 & 0.8 & 0.7 & $1 \cdot 1$ & 0.9 & $1 \cdot 3$ & $1 \cdot 2$ & $1 \cdot 7$ & $2 \cdot 1$ & $2 \cdot 7$ \\
\hline
\end{tabular}


smokers, more likely to have a university education, less likely to live alone and less likely to self-report a history of hypertension or high cholesterol (Table 2). The mean intake of alcohol, fibre, $\mathrm{Na}$ and long-chain $n-3$ was higher and the mean intake of protein and carbohydrate was lower in women in the top quintile of $18: 2 n-6$ intake compared with the bottom quintile. Foods that accounted for variability in $18: 2 n-6$ intake included soya products, nuts, mayonnaise and salad dressing.

We did not find a significant association between 18:3n-3 intake and the incidence of HF hospitalisation or mortality in models accounting for age and other covariates (Table 3). The relationships did not vary by intake of long-chain $n-3$ ( $P$ for interaction=0.29) or by intake of $18: 2 n-6$ ( $P$ for interaction $=0 \cdot 81$ ). The RR for a 1 standard deviation difference in $18: 3 n-3$ as the percentage of total fat $(0 \cdot 4 \%$ of total fat) was $1.00(95 \%$ CI $0.91,1.10)$ before adjustment for measurement error and 1.01 (95\% CI 0.55, 1.85) after adjustment for measurement error.

18:2n-6 was also not significantly associated with the incidence of HF. We did not find evidence that the relationship between 18:2n-6 and HF varied by long-chain $n-3$ intake ( $P$ for interaction $=0.54)$. The RR for a 1 standard deviation difference in $18: 2 n-6$ as the percentage of total fat $(2 \cdot 7 \%$ of total fat) was $1.04(95 \%$ CI $0.95,1.14)$ before adjustment for measurement error and 1.20 (95\% CI 0.54, 2.66) after adjustment for measurement error.

In nutrient replacement models, $18: 3 n-3$ was not significantly associated with HF, but the RR for the top quintile compared with the bottom quintile of $18: 2 n-6$ was 1.57 (95\% CI $1 \cdot 06,2 \cdot 34)$. This estimate was greatly attenuated when either carbohydrate or saturated fat was removed from the model, and there was strong evidence of model-fitting problems due to multicollinearity. We did not find significant associations between the consumption of soya products, nuts, mayonnaise or salad dressing one or more times per week and the incidence of HF events (Table 4). Results were not materially different when the first 2 years of follow-up were excluded.

\section{Discussion}

In this population of middle-aged and older women, there was no significant association of $18: 3 n-3$ or $18: 2 n-6$ or their major foods sources with the incidence of $\mathrm{HF}$ hospitalisation or mortality. We did not find evidence that the associations differed by intake of other PUFA. We had hypothesised that both $18: 3 n-3$ and $18: 2 n-6$ would have inverse associations with the incidence of HF. However, intake of $18: 3 n-3$ was relatively

Table 2. Characteristics of 36234 women aged $48-83$ years by linoleic acid consumption

(Mean values and standard deviations; percentages)

\begin{tabular}{|c|c|c|c|c|c|c|c|c|c|c|}
\hline & \multicolumn{2}{|c|}{ Quintile 1} & \multicolumn{2}{|c|}{ Quintile 2} & \multicolumn{2}{|c|}{ Quintile 3} & \multicolumn{2}{|c|}{ Quintile 4} & \multicolumn{2}{|c|}{ Quintile 5} \\
\hline & Mean & SD & Mean & SD & Mean & SD & Mean & SD & Mean & SD \\
\hline Age (years) & $64 \cdot 0$ & $9 \cdot 4$ & $62 \cdot 6$ & $9 \cdot 2$ & $61 \cdot 5$ & $9 \cdot 0$ & $60 \cdot 4$ & 8.7 & 59.5 & $8 \cdot 7$ \\
\hline BMI $\left(\mathrm{kg} / \mathrm{m}^{2}\right)$ & $24 \cdot 9$ & 3.9 & $25 \cdot 0$ & $3 \cdot 9$ & $25 \cdot 0$ & 3.9 & $25 \cdot 0$ & 3.9 & $24 \cdot 8$ & 3.9 \\
\hline $\begin{array}{l}\text { Physical activity (metabolic } \\
\text { equivalent } h / d \text { ) }\end{array}$ & $42 \cdot 3$ & 4.9 & $42 \cdot 5$ & $4 \cdot 6$ & $42 \cdot 6$ & $4 \cdot 7$ & $42 \cdot 5$ & $4 \cdot 7$ & $42 \cdot 3$ & $4 \cdot 8$ \\
\hline \multicolumn{11}{|l|}{ Cigarette smoking (\%) } \\
\hline Current & \multicolumn{2}{|c|}{$21 \cdot 8$} & \multicolumn{2}{|c|}{$21 \cdot 3$} & \multicolumn{2}{|c|}{$21 \cdot 8$} & \multicolumn{2}{|c|}{$23 \cdot 3$} & \multicolumn{2}{|c|}{$25 \cdot 9$} \\
\hline Past & \multicolumn{2}{|c|}{$21 \cdot 0$} & \multicolumn{2}{|c|}{$23 \cdot 1$} & \multicolumn{2}{|c|}{21.4} & \multicolumn{2}{|c|}{$23 \cdot 2$} & \multicolumn{2}{|c|}{$24 \cdot 1$} \\
\hline Never & \multicolumn{2}{|c|}{$57 \cdot 2$} & \multicolumn{2}{|c|}{$55 \cdot 6$} & \multicolumn{2}{|c|}{$56 \cdot 8$} & \multicolumn{2}{|c|}{53.5} & \multicolumn{2}{|c|}{$50 \cdot 0$} \\
\hline \multicolumn{11}{|l|}{ Education (\%) } \\
\hline Less than high school & \multicolumn{2}{|c|}{$75 \cdot 2$} & \multicolumn{2}{|c|}{$75 \cdot 6$} & \multicolumn{2}{|c|}{$75 \cdot 4$} & \multicolumn{2}{|c|}{$74 \cdot 2$} & \multicolumn{2}{|c|}{$68 \cdot 1$} \\
\hline High school & \multicolumn{2}{|c|}{$7 \cdot 3$} & & & & & & & & \\
\hline University & & & & & & & & & & \\
\hline Living alone (\%) & & & & & & & & & & \\
\hline History of hypertension (\%) & & & & & & & & & & \\
\hline History of high cholesterol (\%) & & & & & & & & & & \\
\hline $\begin{array}{l}\text { Postmenopausal hormone } \\
\text { therapy }(\%)\end{array}$ & & & & & & & & & & \\
\hline $\begin{array}{l}\text { Family history of myocardial } \\
\text { infarction (\%) }\end{array}$ & & & & & & & & & & \\
\hline Energy intake (kJ/d) & 7360 & 2360 & 7268 & 2130 & 7222 & 2075 & 7222 & 2100 & 7314 & 2301 \\
\hline Alcohol (g/d) & $4 \cdot 1$ & $6 \cdot 2$ & $4 \cdot 0$ & $5 \cdot 2$ & 3.9 & $4 \cdot 6$ & $4 \cdot 2$ & $4 \cdot 7$ & $4 \cdot 7$ & $5 \cdot 3$ \\
\hline Fibre $(\mathrm{g} / \mathrm{d})$ & $21 \cdot 1$ & $6 \cdot 1$ & $22 \cdot 0$ & $5 \cdot 4$ & $22 \cdot 4$ & $5 \cdot 2$ & $22 \cdot 4$ & $5 \cdot 1$ & $22 \cdot 4$ & 5.5 \\
\hline $\mathrm{Na}(\mathrm{g} / \mathrm{d})$ & 2308 & 378 & 2469 & 333 & 2550 & 328 & 2627 & 360 & 2669 & 433 \\
\hline Protein $(g / d)$ & $72 \cdot 7$ & $14 \cdot 7$ & $71 \cdot 0$ & $11 \cdot 0$ & $70 \cdot 3$ & $9 \cdot 9$ & $69 \cdot 8$ & $10 \cdot 0$ & 68.5 & $10 \cdot 4$ \\
\hline Carbohydrate (g/d) & 219 & 31 & 214 & 26 & 211 & 24 & 207 & 23 & 202 & 24 \\
\hline Saturated fat $(\mathrm{g} / \mathrm{d})$ & $27 \cdot 1$ & $7 \cdot 4$ & $27 \cdot 4$ & $6 \cdot 3$ & $27 \cdot 4$ & $6 \cdot 1$ & $27 \cdot 4$ & $5 \cdot 9$ & $27 \cdot 1$ & $5 \cdot 9$ \\
\hline Linoleic acid $(\mathrm{g} / \mathrm{d})$ & $4 \cdot 4$ & 0.5 & $5 \cdot 3$ & $0 \cdot 2$ & $5 \cdot 9$ & $0 \cdot 2$ & $6 \cdot 5$ & 0.2 & $8 \cdot 4$ & $1 \cdot 8$ \\
\hline$\alpha$-Linolenic acid $(\mathrm{g} / \mathrm{d})$ & 0.92 & 0.15 & 1.07 & 0.14 & $1 \cdot 16$ & 0.15 & $1 \cdot 26$ & 0.16 & 1.48 & 0.27 \\
\hline Long-chain $n$-3 PUFA (g/d) & 0.31 & 0.26 & 0.33 & 0.26 & 0.35 & 0.24 & 0.36 & 0.23 & 0.37 & 0.26 \\
\hline Soya products (servings/week) & $0 \cdot 1$ & $0 \cdot 2$ & $0 \cdot 1$ & 0.3 & $0 \cdot 2$ & $0 \cdot 3$ & 0.3 & 0.5 & $0 \cdot 7$ & $1 \cdot 7$ \\
\hline Nuts (servings/week) & $0 \cdot 2$ & 0.3 & $0 \cdot 2$ & 0.4 & 0.3 & 0.4 & 0.4 & 0.6 & 0.6 & 1.5 \\
\hline Mayonnaise (servings/week) & 0.2 & 0.4 & 0.3 & 0.4 & 0.4 & 0.4 & 0.5 & 0.5 & 0.8 & 1.7 \\
\hline Salad dressing (servings/week) & 0.5 & $1 \cdot 0$ & 0.7 & $1 \cdot 1$ & 0.8 & $1 \cdot 3$ & $1 \cdot 1$ & 1.5 & $2 \cdot 2$ & $2 \cdot 6$ \\
\hline
\end{tabular}


Table 3. $\alpha$-Linolenic acid, linolenic acid and incidence of heart failure hospitalisation or mortality among 36234 women aged $48-83$ years

\begin{tabular}{|c|c|c|c|c|c|c|}
\hline & Quintile 1 & Quintile 2 & Quintile 3 & Quintile 4 & Quintile 5 & $P_{\text {trend }}$ \\
\hline \multicolumn{7}{|l|}{$\alpha$-Linolenic acid } \\
\hline Median & 0.88 & 1.03 & $1 \cdot 15$ & $1 \cdot 28$ & 1.50 & \\
\hline Range & $0.34-0.96$ & $0.97-1.09$ & $1 \cdot 10-1 \cdot 21$ & $1 \cdot 22-1 \cdot 36$ & $1.37-4.85$ & \\
\hline Cases & 150 & 143 & 120 & 128 & 110 & \\
\hline Person-years & 62298 & 62678 & 62655 & 62622 & 62965 & \\
\hline $\mathrm{RR}^{*}$ & 1 & 1.09 & 0.97 & 1.01 & 0.87 & 0.22 \\
\hline $95 \% \mathrm{Cl}^{*}$ & Reference & $0.87,1.37$ & $0.76,1.24$ & $0.80,1.28$ & $0.68,1.12$ & \\
\hline $\mathrm{RR} \dagger$ & 1 & $1 \cdot 10$ & 0.99 & 1.05 & 0.91 & 0.41 \\
\hline $95 \% \mathrm{Cl} \dagger$ & Reference & $0.87,1.38$ & $0.77,1.26$ & $0.82,1.33$ & $0.71,1.17$ & \\
\hline \multicolumn{7}{|l|}{ Linoleic acid } \\
\hline Median & 4.6 & $5 \cdot 3$ & 5.9 & 6.5 & $7 \cdot 8$ & \\
\hline Range & $1 \cdot 7-5 \cdot 0$ & $5 \cdot 1-5 \cdot 6$ & $5 \cdot 7-6 \cdot 1$ & $6 \cdot 2-7 \cdot 0$ & $7 \cdot 1-31 \cdot 2$ & \\
\hline Cases & 180 & 137 & 125 & 100 & 109 & \\
\hline Person-years & 61664 & 62529 & 62718 & 63036 & 63271 & \\
\hline $\mathrm{RR}^{*}$ & 1 & 0.91 & 0.97 & 0.90 & 1.07 & 0.67 \\
\hline $95 \% \mathrm{Cl}^{*}$ & Reference & $0.73,1.14$ & $0.78,1.23$ & $0.70,1.15$ & $0.84,1.35$ & \\
\hline $\mathrm{RR} \dagger$ & 1 & 0.93 & 1.03 & 0.92 & $1 \cdot 14$ & 0.36 \\
\hline $95 \% \mathrm{Cl} \dagger$ & Reference & $0.74,1 \cdot 16$ & $0.81,1.31$ & $0.71,1.20$ & $0.88,1.46$ & \\
\hline
\end{tabular}

RR, rate ratio.

${ }^{*}$ Cox proportional hazards model accounting for age.

†Cox proportional hazards model accounting for age and adjusted for BMI, physical activity, energy intake, alcohol consumption, fibre consumption, Na consumption, education, family history of myocardial infarction at $<60$ years, cigarette smoking, living alone, postmenopausal hormone use, self-reported history of hypertension, and self-reported history of high cholesterol.

low; an association between $18: 3 n-3$ and HF may be evident at higher levels of intake than observed in the Swedish Mammography Cohort. The present results are consistent with a recent large study of women from the USA, which also failed to find an association between $18: 3 n-3$ and $\mathrm{HF}^{(16)}$. In addition, we were not able to examine independent effects of $18: 3 n-3$ and $18: 2 n-6$ because of the correlation between them.

There is strong evidence from numerous randomised, controlled feeding studies that PUFA reduced LDL-cholesterol and increased HDL-cholesterol when substituted for carbohydrate ${ }^{(21)}$. However, dyslipidaemia is a minor risk factor for $\mathrm{HF}^{(3)}$. Dyslipidaemia can cause $\mathrm{CHD}$, a major risk factor for $\mathrm{HF}^{(3)}$. Intake of both $18: 3 n-3$ and $18: 2 n-6$ has been inversely associated with incident $\mathrm{CHD}$, but the results have not been consistent and are not conclusive ${ }^{(13-15,20)}$. In the present study, we excluded women with prevalent MI, and followup may not have been long enough to complete a proposed pathway from low $18: 3 n-3$ and $18: 2 n-6$ intake to dyslipidaemia to MI to HF.

$18: 3 n-3$ can be converted into long-chain $n-3$ fatty acids that have a number of beneficial effects, including potentially reducing post-MI mortality and mortality among people with
$\mathrm{HF}^{(4,5,17)}$, decreasing propensity to arrhythmia in many settings ${ }^{(30)}$, and, at high doses, reducing TAG concentrations ${ }^{(31)}$. Our previous work and work of others suggested that moderate intake of long-chain $n$ - 3 fatty acids may decrease the risk of $\mathrm{HF}^{(8-11)}$. In one study, there was an inverse association between dark fish, a major dietary source of long-chain $n-3$ fatty acids, and HF but no association with long-chain $n-3$ fatty acids themselves ${ }^{(16)}$. Conversion of $18: 3 n-3$ to longchain $n-3$ fatty acids is inefficient and seems to be affected by the intake of $18: 2 n-6$ and long-chain $n-3$ as well as variations in fatty acid desaturase genes ${ }^{(12,32)}$. Both $18: 3 n-3$ and $18: 2 n-6$ are essential fatty acids for humans, which must be obtained from the diet. The present study examined the range of intake reported by a relatively healthy population rather than frank deficiencies in the nutrients. We were not able to examine higher intakes that are consumed in some populations or are possible through supplementation. It is possible that an effect of $18: 3 n-3$ would be evident in a population with a higher intake of $18: 3 n-3$ or a lower intake of long-chain $n$-3 fatty acids and 18:2n-6. We attempted to address this issue by looking for interactions between $18: 3 n-3$ and the other fatty acids; however, we were limited

Table 4. Intake of high $\alpha$-linolenic acid or linoleic acid foods and incidence of heart failure hospitalisation or mortality among 36234 women aged $48-83$ years

\begin{tabular}{lcccr}
\hline & $\begin{array}{c}\text { Correlation with } \\
\alpha \text {-linolenic acid }\end{array}$ & $\begin{array}{c}\text { Correlation with } \\
\text { linoleic acid }\end{array}$ & $\begin{array}{c}\text { RR for consumption } \geq 1 \\
\text { time/week }\end{array}$ & $95 \% \mathrm{Cl}$ \\
\hline Soya products & 0.29 & 0.29 & 1.24 & $0.80,1.92$ \\
Nuts & 0.08 & 0.23 & 0.73 & $0.47,1 \cdot 15$ \\
Mayonnaise & 0.29 & 0.38 & 1.08 & $0.80,1.44$ \\
Salad dressing & 0.38 & 0.41 & 0.88 & $0.71,1 \cdot 10$ \\
\hline
\end{tabular}

$\mathrm{RR}$, rate ratio.

* Cox proportional hazards model accounting for age and adjusted for BMI, physical activity, energy intake, alcohol consumption, fibre consumption, Na consumption, education, family history of myocardial infarction at $<60$ years, cigarette smoking, living alone, postmenopausal hormone use, self-reported history of hypertension, and self-reported history of high cholesterol. 
to only examining patterns of consumption that exist in this population.

$18: 3 n-3$ and $18: 2 n-6$ are consumed together in foods and are highly correlated. It is difficult to separate out effects of the two types of polyunsaturated fat, which limits the conclusions we can draw about their biological action. In this population, soya products, mayonnaise and salad dressing contributed importantly to the variability in both $18: 3 n-3$ and 18:2n-6. Nutrient replacement models, which are often used when examining the relationships of macronutrients with disease, were not reliable in the present study because of multicollinearity. We therefore could not determine the independent effects of $18: 3 n-3$ and $18: 2 n-6$. Feeding studies that directly manipulate specific fatty acids would be able to determine specific effects of $18: 3 n-3$ and $18: 2 n-6$. In order to realise any public health benefit from differentially altering $18: 3 n-3$ and $18: 2 n-6$ intake, changes to the food supply to provide these fats independent of one another would be necessary. We expect some misclassification of $18: 3 n-3$ and 18:2n-6 intake because dietary intake was measured using questionnaires. This misclassification limits our ability to detect moderately sized effects of nutrients. We used regression calibration to try to take the measurement errors into account; however, this technique relies on a number of strong assumptions and does not fully account for the bias towards the null that results from random errors ${ }^{(25)}$. $\mathrm{HF}$ is a clinical syndrome with variable presentation and aetiology, and we did not have information on HF subtype. Although Swedish inpatient and cause-of-death registers are almost complete and the accuracy of HF diagnosis has been shown to be high ${ }^{(26)}$, the registers only captured cases that result in hospitalisation or death. Therefore, the present results may not be generalisable to HF treated on an outpatient basis. While the present study had sufficient power to detect a $30 \%$ decrease in the rate of $\mathrm{HF}$ associated with the fatty acids, we did not have power to reliably detect more subtle associations. Finally, as with all observational studies, we were not able to rule out bias due to residual or unmeasured confounding. In particular, it can be difficult to distinguish between the effect of nutrients and the effect of the foods that supply those nutrients.

In summary, we did not find evidence for an association between $18: 3 n-3$ or $18: 2 n-6$ intake and the incidence of HF hospitalisation and mortality in this population of women from central Sweden. The present results may not be generalisable to populations with a higher intake of $18: 3 n-3$ than observed in this population. Further work with other populations and other study designs is needed to determine whether a high intake of $18: 3 n-3$ can prevent $\mathrm{HF}$ and to tease out independent effects of $18: 3 n-3$ and $18: 2 n-6$.

\section{Acknowledgements}

This study was supported by grants from the Swedish Research Council/Committee for Infrastructure, Swedish Research Council/Committee for Medicine, and the Swedish Foundation for International Cooperation in Research and Higher Education. None of the authors has any conflicts of interest related to this work. The contribution of each author is as follows: E. B. L., A. W., N. H. and M. A. M. designed the study; A. W. and N. H. collected the data; E. B. L. and N. H. performed the analysis; E. B. L. wrote the manuscript; A. W., N. H. and M. A. M. revised the manuscript.

\section{References}

1. Lloyd-Jones D, Adams RJ, Brown TM, et al. (2010) Heart disease and stroke statistics-2010 update: a report from the American Heart Association. Circulation 121, e46-e215.

2. Levy D, Kenchaiah S, Larson MG, et al. (2002) Long-term trends in the incidence of and survival with heart failure. $N$ Engl J Med 347, 1397-1402.

3. Schocken DD, Benjamin EJ, Fonarow GC, et al. (2008) Prevention of heart failure: a scientific statement from the American Heart Association Councils on Epidemiology and Prevention, Clinical Cardiology, Cardiovascular Nursing, and High Blood Pressure Research; Quality of Care and Outcomes Research Interdisciplinary Working Group; and Functional Genomics and Translational Biology Interdisciplinary Working Group. Circulation 117, 2544-2565.

4. Anonymous (1999) Dietary supplementation with $n$-3 polyunsaturated fatty acids and vitamin E after myocardial infarction: results of the GISSI-Prevenzione trial. Gruppo Italiano per lo Studio della Sopravvivenza nell'Infarto miocardico. Lancet 354, 447-455.

5. GISSI-HF Investigators (2008) Effect of $n$-3 polyunsaturated fatty acids in patients with chronic heart failure (the GISSIHF trial): a randomised, double-blind, placebo-controlled trial. Lancet 372, 1223-1230.

6. Albert CM, Hennekens CH, O'Donnell CJ, et al. (1998) Fish consumption and risk of sudden cardiac death. JAMA $\mathbf{2 7 9}$ $23-28$.

7. Wang C, Harris WS, Chung M, et al. (2006) n-3 Fatty acids from fish or fish-oil supplements, but not alpha-linolenic acid, benefit cardiovascular disease outcomes in primaryand secondary-prevention studies: a systematic review. $A m$ J Clin Nutr 84, 5-17.

8. Mozaffarian D, Bryson CL, Lemaitre RN, et al. (2005) Fish intake and risk of incident heart failure. J Am Coll Cardiol 45, 2015-2021.

9. Yamagishi K, Iso H, Date C, et al. (2008) Fish, omega-3 polyunsaturated fatty acids, and mortality from cardiovascular diseases in a nationwide community-based cohort of Japanese men and women the JACC (Japan Collaborative Cohort Study for Evaluation of Cancer Risk) Study. J Am Coll Cardiol 52, 988-996.

10. Levitan EB, Wolk A \& Mittleman MA (2009) Fish consumption, marine omega- 3 fatty acids, and incidence of heart failure: a population-based prospective study of middle-aged and elderly men. Eur Heart J 30, 1495-1500.

11. Levitan EB, Wolk A \& Mittleman MA (2010) Fatty fish, marine omega-3 fatty acids and incidence of heart failure. Eur J Clin Nutr 64, 587-594.

12. Brenna JT (2002) Efficiency of conversion of alpha-linolenic acid to long chain $n-3$ fatty acids in man. Curr Opin Clin Nutr Metab Care 5, 127-132.

13. Campos H, Baylin A \& Willett WC (2008) Alpha-linolenic acid and risk of nonfatal acute myocardial infarction. Circulation 118, 339-345.

14. Mozaffarian D, Ascherio A, Hu FB, et al. (2005) Interplay between different polyunsaturated fatty acids and risk of coronary heart disease in men. Circulation 111, 157-164. 
15. Mente A, de Koning L, Shannon HS, et al. (2009) A systematic review of the evidence supporting a causal link between dietary factors and coronary heart disease. Arch Intern Med 169, 659-669.

16. Belin RJ, Greenland P, Martin L, et al. (2011) Fish intake and the risk of incident heart failure: the Women's Health Initiative. Circ Heart Fail 4, 404-413.

17. Kromhout D, Giltay EJ \& Geleijnse JM (2010) n-3 Fatty acids and cardiovascular events after myocardial infarction. $N$ Engl J Med 363, 2015-2026.

18. Kris-Etherton PM, Taylor DS, Yu-Poth S, et al. (2000) Polyunsaturated fatty acids in the food chain in the United States. Am J Clin Nutr 71, 179S-188S.

19. Harris WS, Mozaffarian D, Rimm E, et al. (2009) Omega-6 fatty acids and risk for cardiovascular disease: a science advisory from the American Heart Association Nutrition Subcommittee of the Council on Nutrition, Physical Activity, and Metabolism; Council on Cardiovascular Nursing; and Council on Epidemiology and Prevention. Circulation 119, 902-907.

20. Czernichow S, Thomas D \& Bruckert E (2010) $n$-6 Fatty acids and cardiovascular health: a review of the evidence for dietary intake recommendations. Br J Nutr 104, 788-796.

21. Mensink RP, Zock PL, Kester AD, et al. (2003) Effects of dietary fatty acids and carbohydrates on the ratio of serum total to HDL cholesterol and on serum lipids and apolipoproteins: a meta-analysis of 60 controlled trials. Am J Clin Nutr 77, 1146-1155.

22. Oh K, Hu FB, Manson JE, et al. (2005) Dietary fat intake and risk of coronary heart disease in women: 20 years of follow-up of the Nurses' Health Study. Am J Epidemiol 161, 672-679.

23. Wolk A, Larsson SC, Johansson JE, et al. (2006) Long-term fatty fish consumption and renal cell carcinoma incidence in women. JAMA 296, 1371-1376.

24. Bergström L, Kylberg E, Hagman U, et al. (1991) The food composition database KOST: the National Administration's information system for nutritive values of food. Var Foda 43, 439-447.

25. Willett WC (1998) Nutritional Epidemiology, 2nd ed. New York, NY: Oxford University Press.

26. Ingelsson E, Arnlov J, Sundstrom J, et al. (2005) The validity of a diagnosis of heart failure in a hospital discharge register. Eur J Heart Fail 7, 787-791.

27. Schafer JL (1997) Analysis of Incomplete Multivariate Data. Boca Raton: CRC Press.

28. Collett D (2003) Modelling Survival Data in Medical Research, 2nd ed. Boca Raton: Chapman \& Hall/CRC.

29. Schoenfeld DA \& Richter JR (1982) Nomograms for calculating the number of patients needed for a clinical trial with survival as an endpoint. Biometrics 38, 163-170.

30. Reiffel JA \& McDonald A (2006) Antiarrhythmic effects of omega-3 fatty acids. Am J Cardiol 98, 50i-60i.

31. Harris WS, Ginsberg HN, Arunakul N, et al. (1997) Safety and efficacy of Omacor in severe hypertriglyceridemia. J Cardiovasc Risk 4, 385-391.

32. Glaser C, Heinrich J \& Koletzko B (2010) Role of FADS1 and FADS2 polymorphisms in polyunsaturated fatty acid metabolism. Metabolism 59, 993-999. 